\title{
Light Water Reactor Sustainability Constellation Pilot Project FY12 Summary Report
}

R. Johansen

September 2012

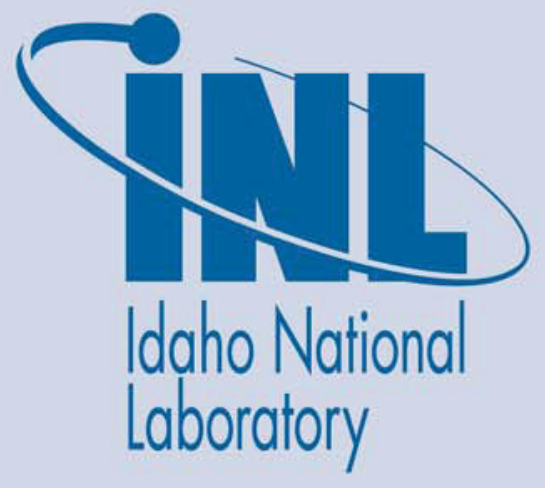

The INL is a U.S. Department of Energy National Laboratory operated by Battelle Energy Alliance 


\section{DISCLAIMER}

This information was prepared as an account of work sponsored by an agency of the U.S. Government. Neither the U.S. Government nor any agency thereof, nor any of their employees, makes any warranty, expressed or implied, or assumes any legal liability or responsibility for the accuracy, completeness, or usefulness, of any information, apparatus, product, or process disclosed, or represents that its use would not infringe privately owned rights. References herein to any specific commercial product, process, or service by trade name, trade mark, manufacturer, or otherwise, does not necessarily constitute or imply its endorsement, recommendation, or favoring by the U.S. Government or any agency thereof. The views and opinions of authors expressed herein do not necessarily state or reflect those of the U.S. Government or any agency thereof. 


\title{
Light Water Reactor Sustainability Constellation Pilot Project FY12 Summary Report
}

\author{
R. Johansen
}

September 2012

Idaho National Laboratory Idaho Falls, Idaho 83415

http://www.inl.gov

Prepared for the

U.S. Department of Energy

Office of Nuclear Energy

Under DOE Idaho Operations Office

Contract DE-AC07-05ID14517 



\section{CONTENTS}

ACRONYMS vii

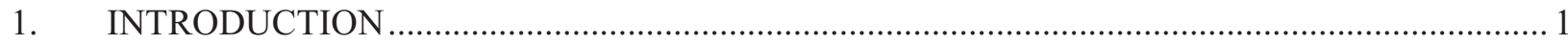

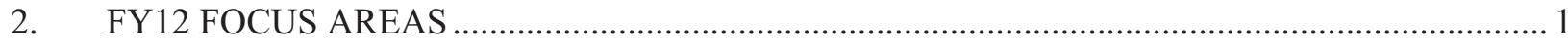

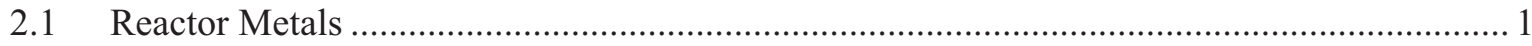

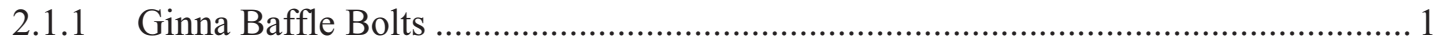

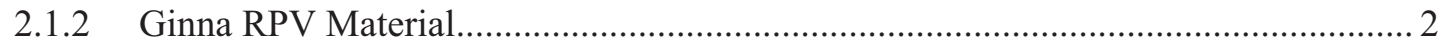

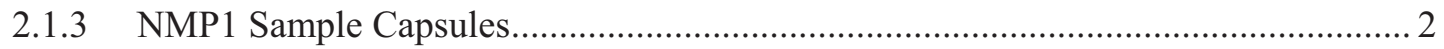

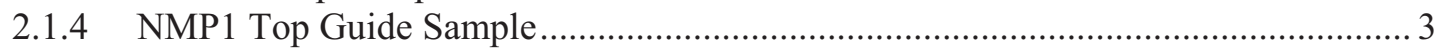

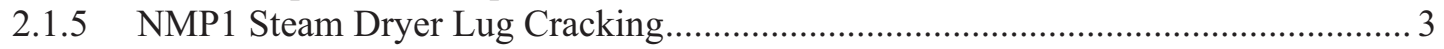

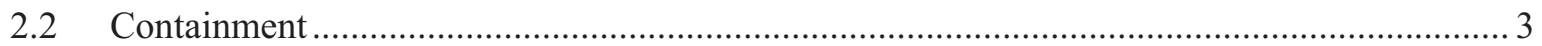

2.2.1 Ginna Tendon Monitoring ............................................................................... 3

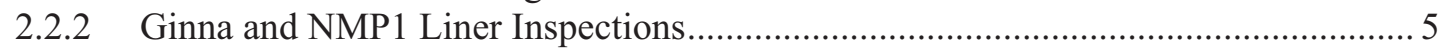

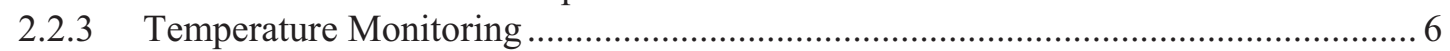

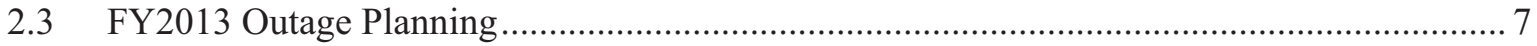

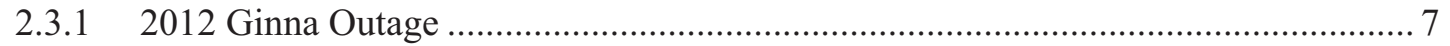

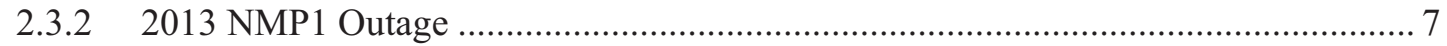

3. RECOMMENDATIONS/FOLLOW-UP ACTIVITIES …..................................................... 8

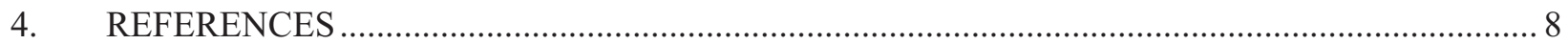

\section{FIGURES}

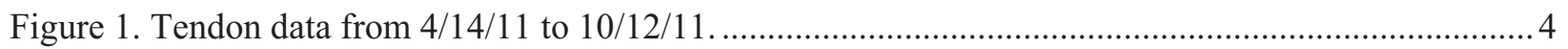

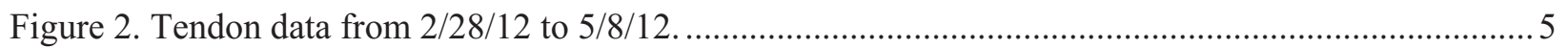

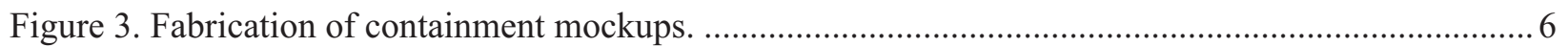

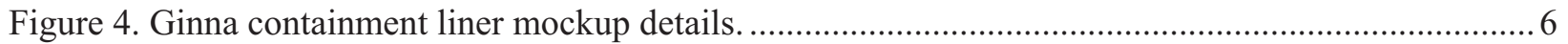




\section{ACRONYMS}

BWR Boiling Water Reactor

CENG Constellation Energy Nuclear Group

DIC Digital Image Correlation

DOE Department of Energy

EPRI Electric Power Research Institute

Ginna R.E. Ginna Nuclear Power Plant

IASCC Irradiation-Assisted Stress Corrosion Cracking

INL Idaho National Laboratory

ISP Integrated Surveillance Program

LTO Long Term Operation Program (EPRI)

LWRS Light Water Reactor Sustainability Program (DOE)

MAaD Materials Aging and Degradation Pathway in LRWS

NMP1 Nine Mile Point Unit 1 Nuclear Power Plant

ORNL Oak Ridge National Laboratory

PWR Pressurized Water Reactor

RPV reactor pressure vessel 


\section{Light Water Reactor Sustainability Constellation Pilot Project FY12 Summary Report}

\section{INTRODUCTION}

As a partner in research for operations beyond 60 years, Constellation Energy Nuclear Group (CENG) has volunteered two of its nuclear power plants: R. E. Ginna and Nine Mile Point Unit 1 (NMP1). The coordinated work to be performed with CENG is a joint effort involving the Electric Power Research Institute (EPRI) Long Term Operation (LTO) Program and the Department of Energy (DOE) Light Water Reactor Sustainability (LWRS) Research \& Development Program. The following report summarizes the activities performed in FY11 at Ginna and NMP1 power plants.

The R. E. Ginna nuclear power plant is located on Lake Ontario approximately 20 miles from Rochester, NY. The $581 \mathrm{MW}$ capacity unit is a pressurized water reactor (PWR) which began commercial operation in 1970. The Nine Mile Point Unit 1 (NMP1) nuclear power plant is located on Lake Ontario approximately 40 miles from Syracuse, NY. The 620 MW capacity unit is a boiling water reactor (BWR) which began commercial operation in 1969. Both units have entered into their 60 year license renewal period, which makes them ideal units to gain further insight into the potential issues for license renewal beyond 60 years.

This report summarizes the activities in focus areas performed from October 1, 2011 through September 30, 2012. (FY12). Refer to INL/EXT-11-23461, Light Water Reactor Sustainability Constellation Pilot Project FY11 Summary Report for the period from October 1, 2010 through September 30, 2011. (FY11)

\section{FY12 FOCUS AREAS}

\subsection{Reactor Metals}

\subsubsection{Ginna Baffle Bolts}

Material degradation of the baffle-former bolts has been identified as a reactor vessel internals aging issue since the 1980s. In 1999, the utility operating Ginna Station (Rochester Gas and Electric) was acting in a proactive manner relative to potential cracking due to SCC and IASCC, as well as other possible degradation mechanisms. The original baffle-former bolt material is Type 347 stainless steel, which some data suggest could have a more pronounced susceptibility to damage than other stainless steels. Cracking of the bolts generally will occur at the shank to bolt head interface, which makes it impossible to see using visual testing (VT) methods since the head is captured with a weld and locking cup. Therefore, current guidance is to use ultrasonic testing (UT) methods to inspect $100 \%$ of the accessible bolts or justify a plant-specific plan, such as using a minimum integrity bolt pattern.

As result of the industry-wide programs on baffle bolt cracking, the Ginna plant replaced 56 baffle bolts in 1999. Some bolts were sent out for evaluation, resulting in approximately 42 bolts left on location at the plant site. As part of the aging management plant for Ginna, approximately 180 bolts were anticipated to be replaced during Spring 2011 outage to ensure the minimum bolting pattern to assure structural integrity under limiting operating conditions. The higher fluence baffle bolts from the 2011 replacement were identified as potential candidates for use in the MAaD pathway studies. However, the bolt material is 347 stainless steel which is not as ideal as 316 stainless steel for the studies.

The original spring 2011 schedule anticipated replacement of 18 bolts per day. However, bolt replacement during the outage proved to be significantly more difficult than anticipated. Only 28 bolts were removed and 3 could not be replaced. Bolt replacement activities were stopped and a recently developed ultrasonic approach was implemented to confirm integrity of the minimum bolting pattern. 
Ultrasonic testing (UT) was performed on twenty-four of the removed bolts and no indications were identified.

The difficulty encountered during the bolt replacement has developed renewed interest in the baffle bolt replacement guidelines. Although the new probe design utilized at Ginna was successful, the use of welded cross bars limits access to the socket for other plant designs. Additionally, long term behavior of the baffle bolts may need to be better understood to support extended operation beyond 60 years. Therefore, further evaluation was recommended to develop a path forward for baffle bolt study. This evaluation was started in the second quarter of FY12. A fundamental requirement of this study is to understand the fluence levels to which the bolts have been exposed. Understanding the fluence levels is key to evaluating the value of the bolts for further evaluation and testing. Currently, this fluence evaluation is in progress and is not anticipated to be completed until October 2012. As a result the evaluation will be completed in FY13. Shipment of any material, based on the evaluation results, will most likely occur in FY14.

\subsubsection{Ginna RPV Material}

Ginna has a surveillance program that has tested five capsules through the current time period. The last tested capsule had a fluence of about $6 \times 10^{19} \mathrm{n} / \mathrm{cm}^{2}$, which represents licensed life out to about 60 years of operation at the inside surface of the RPV wall for the most limiting material. Collection of broken irradiated test specimens from the tested capsules stored at the Westinghouse hot cell facility currently was pursued for shipment to ORNL for microstructure studies under the MAaD Pathway. The following specimens have been identified:

\section{Capsule T}

Broken HAZ Charpy specimen halves from IDs H21 - H30

Broken forging Charpy specimen halves from IDs P21-P30

\section{Capsule S}

Broken HAZ Charpy specimen halves from IDs H31-H42

Broken forging Charpy specimen half from IDs P31- P42

\section{Capsule N}

Broken HAZ Charpy specimen halves from IDs H43 - H54

Broken forging Charpy specimen half from IDs P43 -P54

In FY11 the capsule N specimens have been shipped. In FY12, capsules T and S were shipped. Remaining work with these capsules are under the MAaD Pathway

\subsubsection{NMP1 Sample Capsules}

NMP1 has two supplemental surveillance capsules that were inserted. These capsules have irradiated materials from the previously tested capsules plus non-irradiated base metal from the plant archives that represents the actual material in the RPV; they also are located in positions that have higher lead factors than typical BWRs. Neither of these two capsules are part of the Integrated Surveillance Program (ISP) that the BWRVIP has instituted, so there is no industry plan to test these capsules. However, if the projected fluences are high enough to provide data associated long term operation, testing of the materials in the two capsules could be useful to assess the embrittled conditions for BWRs. Even though the maximum fluence at 80 years of operation may approach the fluence for PWRs early in plant life, the issues of different neutron fluxes and irradiation temperatures can be important. However, preliminary evaluations indicate that the samples need to stay in the reactor longer to reach higher fluence levels before any action is taken. This capsule may be useful in the LWRS program which will be evaluated in FY13. 


\subsubsection{NMP1 Top Guide Sample}

NMP1 has found cracking in the top guide plate similar to that at the Oyster Creek Nuclear Power Plant. The 304 stainless steel top guide plates hold the fuel clusters in position. At Oyster Creek several $3 \times 7$ inch samples were removed from the top guide and were evaluated under the Cooperative IASCC Research (CIR) Program, which is an international research effort designed to address irradiation-assisted stress corrosion cracking (IASCC) in light water reactor components. The results of the study were published in EPRI 1014511 and concluded that IASCC most likely played a role in the initiation and/or propagation of the cracking. However, additional study of the intergranular cracking was suggested to further define the root cause.

The proposed work at NMP1 was to take similar samples as previously obtained from Oyster Creek. These samples would further support the work previously performed and would be of general interest to the industry in support of understanding IASCC in an area of low apparent stress. Several top guide cracks at NMP1 have been identified and are being periodically monitored for crack growth, similar crack locations to those at Oyster Creek are being considered for sampling. Repair of the sample locations would not be necessary based on analyses previously performed at Oyster Creek. The ideal time for obtaining the samples would have been the Spring 2011 outage. However, the preliminary cost estimates for a subcontractor to sample the top guide was prohibitive.

The inspection results from the Spring 2011 examinations did show that some of the indications identified in 2005 have grown. Further review of the possibilities for sampling the top guide and/or utilizing other monitoring methods are being considered. Development of this area will be followed in FY13.

\subsubsection{NMP1 Steam Dryer Lug Cracking}

Indications were identified during the visual inspections of the steam dryer support brackets (or lugs). These indications led to subsequent supplementary UT examination to verify the extent and validity of the cracking indications. The support brackets had been previously inspected in 2001 using a similar inspection technique without any reportable indications being found. A flaw evaluation and crack growth analysis conservatively estimated that the lugs are acceptable for at least on more operating cycle. Re-inspection of the dryer lug is anticipated in 2013 outage. The development of actions and continued monitoring of the cracking will be followed in FY13.

\subsection{Containment}

Concrete monitoring at Ginna and NMP1were focused on augmented tests which can be deployed with available technology:

- Ginna Tendon Monitoring

- Ginna and NMP1 Liner Inspection

- Temperature Monitoring.

\subsubsection{Ginna Tendon Monitoring}

The cylindrical containment wall is pre-stressed with 160 vertical tendons within the wall of the containment that are equally spaced circumferentially around the containment. At penetrations in the containment (e.g. equipment hatch), the tendons are curved around the penetrations. These tendons are incorporated into the containment design in order to keep the cylindrical containment walls in compression during an internal pressurization. 
In FY10, Twenty of the vertical tendons and one exposed circumferential rebar were outfitted with a fiber optic strain gauges (Figures 1 and 2) connected to a Data Acquisition System (DAS) to monitor temperature and strain of the containment wall and tendons. Tendon strain gage data has been collected except for the period from $4 / 14 / 11$ to $10 / 12 / 11$ and from $2 / 28 / 12$ to $5 / 8 / 12$. The data gap resulted from a power disruption which exceeded the capability of the UPS. The data indicates that the tendon load is not significantly affected by shim temperature since the lines are relatively flat except for the SIT (pressure test) performed in early June 2011.

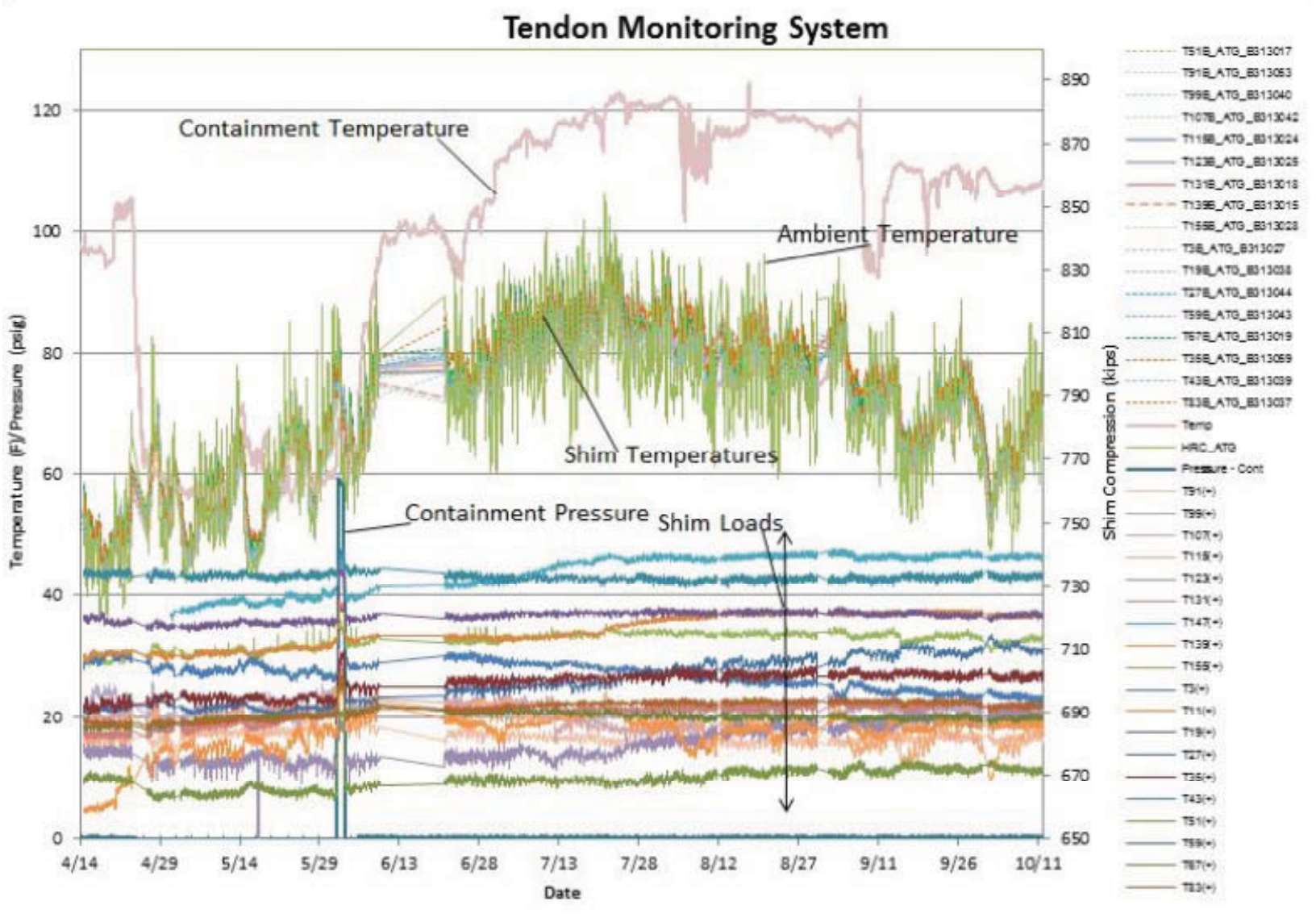

Figure 1. Tendon data from 4/14/11 to 10/12/11. 


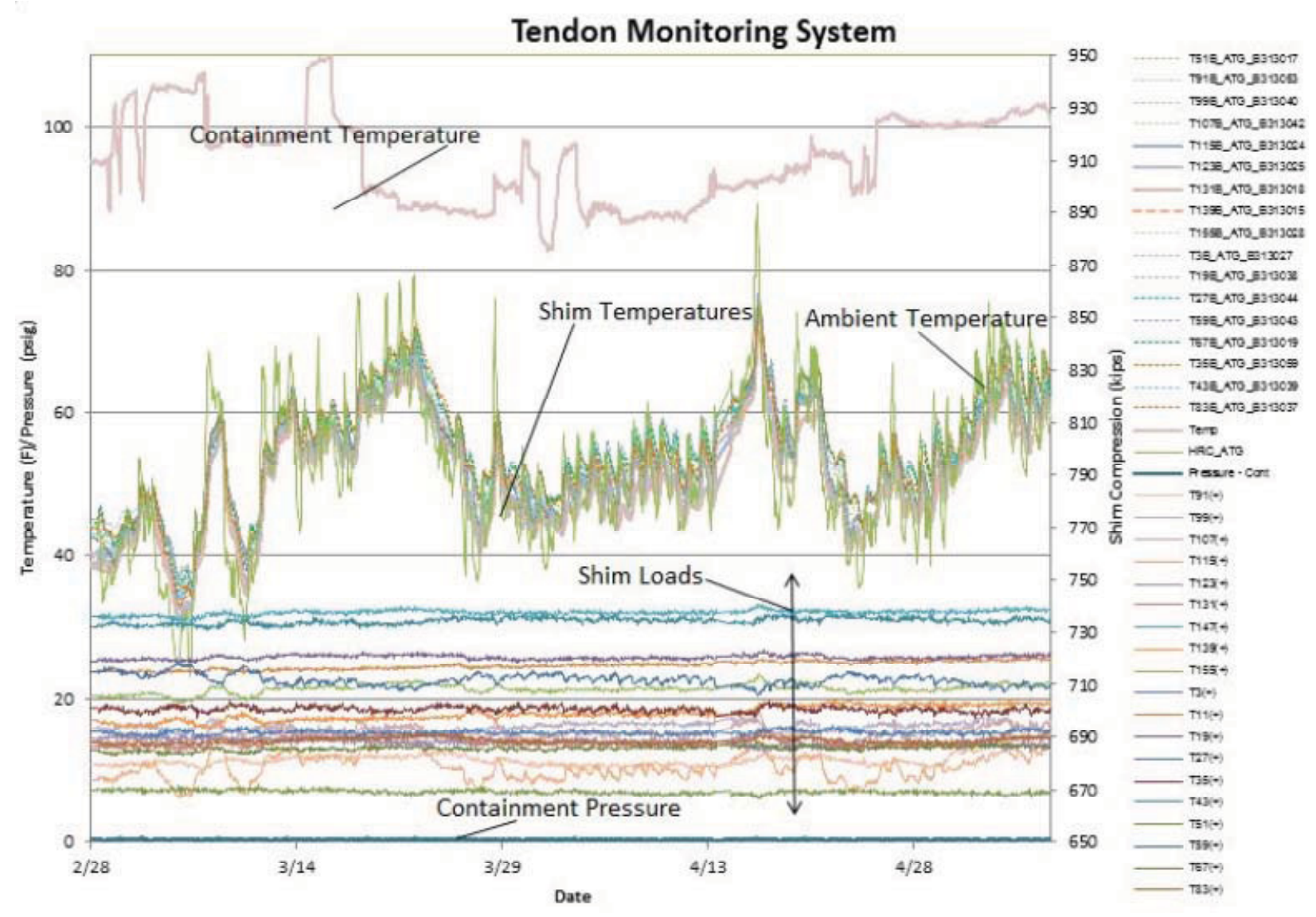

Figure 2. Tendon data from $2 / 28 / 12$ to $5 / 8 / 12$.

Additional information on the Ginna tendon monitoring system and results are in Reference 2.

\subsubsection{Ginna and NMP1 Liner Inspections}

Containment liners are susceptible to degradation mechanisms such as pitting and uniform corrosion. This degradation may occur in accessible and inaccessible regions. Detection of degradation will be tested using existing technology in representative containment configurations.

Mockups of the Ginna and NMP1 containment structures were fabricated in FY12. See Figures 3 and 4 . The concrete mockups simulate of the containment susceptible to corrosion. The mockups are used for testing guided wave and T-SAFT non-destruction contamination techniques for detection degredation of the containment liner. The liners have been fabricated and tested without flaws and with flaws prior to placement of the final concrete. The necessary concrete cure duration will be complete the end of October 2012. Once the concrete has cured, testing is scheduled to resume. The testing will indicate the extent of detection for various flaw sizes in a containment structure. The flaws are located in both accessible an inaccessible regions of the structure.

Upon completion of the mockup demonstration, a determination of the extent of implementation during the 2012 outage will be decided. 


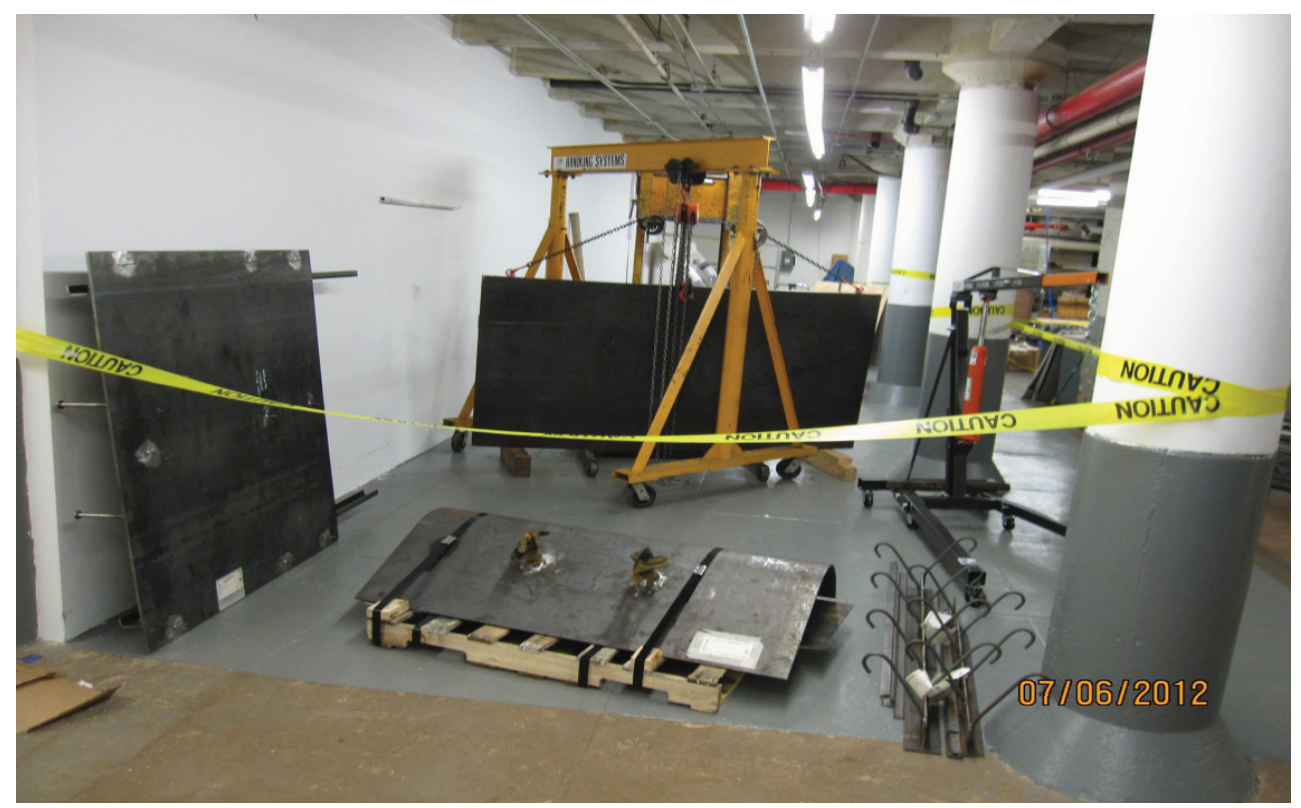

Figure 3. Fabrication of containment mockups.

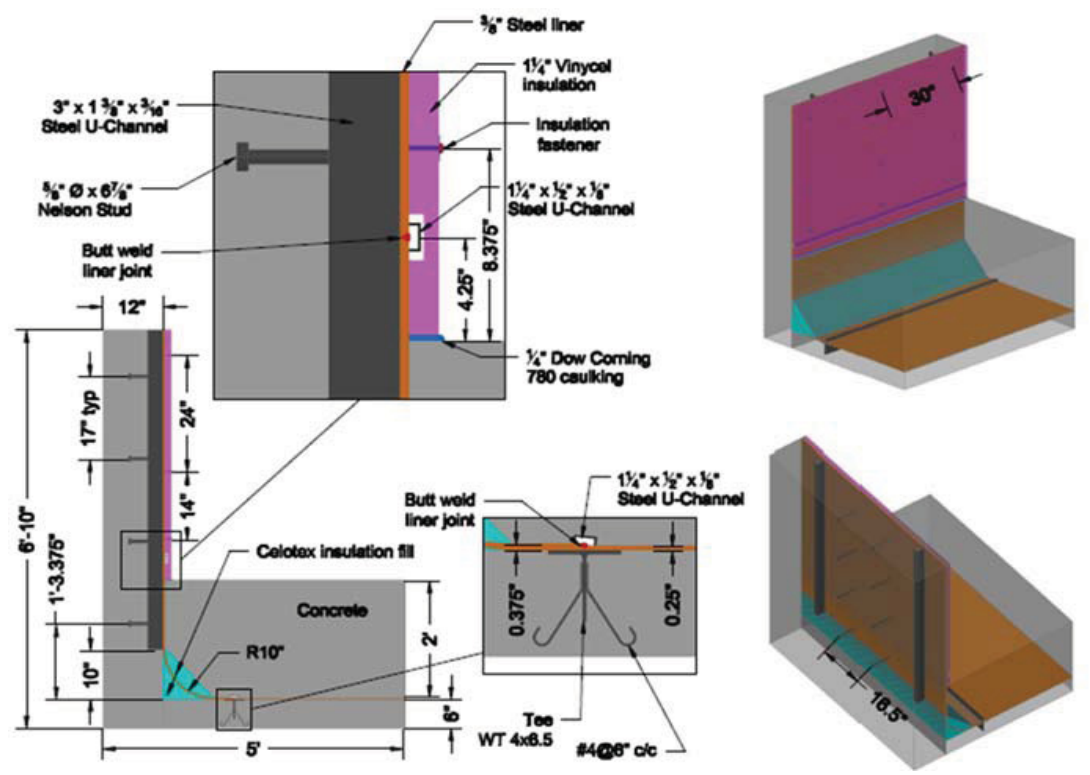

Figure 4. Ginna containment liner mockup details.

\subsubsection{Temperature Monitoring}

Temperature data loggers installed in several locations anticipated to be the hottest regions inside the containment can record temperature data for one cycle and can be retrieved at the next outage. This data can be used to identify areas requiring evaluation due to temperature effects. The data loggers would be mounted to the concrete structures to obtain representative concrete temperatures. Two areas identified at NMP1 are near vessel supports in a region called the "dog house" and near the spent fuel pool. Two areas identified at Ginna are near the top of the pressurizer and in the steam generator compartments. 


\subsection{FY2013 Outage Planning}

\subsubsection{Ginna Outage}

The following areas were planned for the Ginna Outage:

- Temperature Data Logger

Data loggers will be installed in several locations anticipated to be the hottest regions inside the containment. Two areas identified are near the top of the pressurizer and in the steam generator compartments. These data loggers will be in containment for one cycle and provide actual temperature profiles of concrete structures in containment. Temperature is important for determining concrete performance and identifying areas of additional focus due to temperature extremes.

\section{- Concrete Cracking Inside Containment}

A walk-down of the containment will be performed to identify focus areas for further monitoring. A plan for crack characterization and digital mapping will be developed to provide a methodology for crack monitoring and the determination of crack growth in future assessments.

\section{- Interior Dome Condition Assessment}

The interior of the dome has some areas of general corrosion which are difficult to gain access. These areas will be evaluated for to allow for future development of general inspection techniques, if necessary.

Liner inspections will not be performed during the upcoming outage due to timing of the equipment testing. All of the in plant activities require approval by CENG management for implementation. Implementation may be modified or not implemented based on risk and plant availability.

\subsubsection{NMP1 Outage}

The following areas were planned for the NMP1 Outage:

- Top Guide

NMP1 has identified cracking in the top guide plate similar to that at the Oyster Creek Nuclear Power Plant. Several top guide cracks at NMP1 are periodically monitored for crack growth. The inspection results from the spring 2011 examinations indicated growth some of the indications documented in 2005. Plans for possibly sampling some of the top guide material have been discussed, but the costs have been too high for further consideration. Continued review and monitoring of the actions associated with the top guide cracking will be performed as well as evaluations of techniques for sampling the top guide and/or utilizing other monitoring methods.

- Dryer Lugs

During the 2011 inspections, cracks on the dryer lug were discovered. These cracks will be inspected during the 2013 outage and evaluated. Active participation during the 2013 outage is anticipated to monitor inspections and resolutions for applicability and lessons learned for long term operation.

\section{- Temperature Data Logger}

Data loggers will be installed in several locations anticipated to be the hottest regions inside the containment. Two areas identified are near vessel supports in a region called the "dog house" and near the spent fuel pool. These data loggers will be in containment for one cycle and provide actual temperature profiles of concrete structures in containment. Temperature is important for determining concrete performance. Plant data is important in determining the susceptibility to degradation due to temperature extremes. 


\section{- Concrete Cracking Inside Containment}

NMP1 has an effective crack monitoring program. Evaluations and walk-downs of the crack monitoring program and plant will provide additional information on the management of cracks. Characterization of the cracks using digital techniques will provide a quantitative mapping method to augment the current monitoring techniques. Implementation of quantitative mapping techniques will be developed and tested.

\section{- Liner Inspection}

The containment liner is susceptible to degradation. Monitoring of inaccessible areas of the containment liner is an important part of sustainability. A mockup of the drywell shell is currently being fabricated and will be tested using guided wave and T-SAFT non-destructive examination techniques. These mockups will be tested without and with flaws. Upon completion of the mockup demonstration, a determination on the extent of implementation during the 2013 outage will be decided.

\section{- Maintenance Follow}

Participation/monitoring of scheduled inspections of the torus room, torus exterior, coatings, vent headers, downcomers, etc. will be performed. This will provide plant data and parameters for evaluation of effective inspections and may identify areas needing additional research.

All of the in plant activities require approval by CENG management for implementation. Implementation may be modified or not implemented based on risk and plant availability.

\section{RECOMMENDATIONS/FOLLOW-UP ACTIVITIES}

Based on the FY12 activities and discussions with CENG and EPRI personnel the following activities include:

- Continuation of the evaluation of the path forward for the Ginna Baffle bolts. This will include the industry perspective based on long-term operation and the LWRS MAaD pathway goals.

- Participation in and follow of the next outages at Ginna and NMP1 for participation opportunities.

- Evaluation of the NMP1 top guide assembly sampling for cost and benefit and potential LWRS applicability.

- Monitoring of the development for NMP1 steam dryer lug cracking for potential LWRS applicability.

- Continuation of the Containment Inspection Guideline.

- Continued development and testing of non-destructive methods for containment liner inspections.

\section{REFERENCES}

1. William L. Server (ATI Consulting), Letter Report: R.E. Ginna Outage (2012) and Nine Mile Point Unit 1 Outage (2013) Activities, September 2011.

2. Lucius Pitkin, Inc., Augmented Inspection Results, A10551-R003, Rev. 0, Interim Release 2 August 2012.

3. Thomas C Esselman (Lucius Pitkin, Inc), Letter Report: Augmented Containment Inspection PlanNine Mile Point Unit 12013 Outage - Work Performed under BEA Contract 00126388, August 2, 2012.

4. Thomas C Esselman (Lucius Pitkin, Inc), Letter Report: Augmented Containment Inspection PlanR. E. Ginna 2012 Outage - Work Performed under BEA Contract 00126388, July 31, 2012. 